\title{
Catalytic performance of Metal-Organic-Frameworks vs. extra-large pore zeolite UTL in condensation reactions
}

\author{
Mariya Shamzhy ${ }^{1,2}$, Maksym Opanasenko ${ }^{1,2}$, Oleksiy Shvets ${ }^{1,2}$ and Jiří Čejka ${ }^{1 *}$ \\ 1 J. Heyrovský Institute of Physical Chemistry, Department of Synthesis and Catalysis, Academy of Sciences of Czech Republic, Prague, Czech Republic \\ 2 L.V. Pisarzhevskiy Institute of Physical Chemistry, Department of Porous Substances and Materials, National Academy of Sciences of Ukraine, Kyiv, Ukraine
}

\section{Edited by: \\ Marek W. Laniecki, Adam \\ Mickiewicz University, Poland \\ Reviewed by: \\ Roberto Millini, eni s.p.a., Italy Lucjan Chmielarz, Jagiellonian \\ University, Poland}

\section{*Correspondence:}

Jiř Čejka, J. Heyrovský Institute of Physical Chemistry, Department of Synthesis and Catalysis, Academy of Sciences of Czech Republic, v.v.i. Dolejškova 3, 18223 Prague 8, Czech Republic

e-mail: jiri.cejka@jh-inst.cas.cz
Catalytic behavior of isomorphously substituted B-, Al-, Ga-, and Fe-containing extra-large pore UTL zeolites was investigated in Knoevenagel condensation involving aldehydes, Pechmann condensation of 1-naphthol with ethylacetoacetate, and Prins reaction of $\beta$-pinene with formaldehyde and compared with large-pore aluminosilicate zeolite beta and representative Metal-Organic-Frameworks $\mathrm{Cu}_{3}(\mathrm{BTC})_{2}$ and $\mathrm{Fe}(\mathrm{BTC})$. The yield of the target product over the investigated catalysts in Knoevenagel condensation increases in the following sequence: (Al)beta $<$ (Al) UTL $<(\mathrm{Ga}) \mathrm{UTL}<(\mathrm{Fe}) \mathrm{UTL}<\mathrm{Fe}(\mathrm{BTC})<(\mathrm{B}) \mathrm{UTL}<$ $\mathrm{Cu}_{3}(\mathrm{BTC})_{2}$ being mainly related to the improving selectivity with decreasing strength of active sites of the individual catalysts. The catalytic performance of Fe(BTC), containing the highest concentration of Lewis acid sites of the appropriate strength is superior over large-pore zeolite (Al)beta and B-, Al-, Ga-, Fe-substituted extra-large pore zeolites UTL in Prins reaction of $\beta$-pinene with formaldehyde and Pechmann condensation of 1-naphthol with ethylacetoacetate.

Keywords: condensation reactions, MOFs, zeolites, UTL, Prins reaction

\section{INTRODUCTION}

Condensation reactions, in which a carbonyl group undergoes nucleophilic attack by the enol form or enolate carbanions, are powerful tools to form $\mathrm{C}-\mathrm{C}$ bonds affording for easy preparation of useful organic compounds ( $\mathrm{Li}, 2005)$. Among them, Knoevenagel, Pechmann, and Prins reactions, being quite sensitive to the nature of active sites of a catalyst, are particularly interesting to be studied over solid acids, containing active sites of different type and strength.

Knoevenagel condensation of aldehydes with compounds containing active methylene group (Scheme 1) has a wide applications in the synthesis of fine chemicals (Freeman, 1981), biologically active substances (Lai et al., 2003), or precursors for hetero Diels-Alder reactions (Borah et al., 2005). Various homogeneous and heterogeneous catalysts were investigated in Knoevenagel condensation, namely $\mathrm{TiCl}_{4}$ (Green et al., 1985), $\mathrm{ZnCl}_{2}$ (Shanthan and Venkataratnam, 1991), $\mathrm{MgF}_{2}$ (Kumbhare and Sridhar, 2008), $\mathrm{HClO}_{4}-\mathrm{SiO}_{2}$ (Bartoli et al., 2006), $\mathrm{Ni}-\mathrm{SiO}_{2}$ (Rajasekhar Pullabhotla et al., 2009), phosphates (Bennazha et al., 2003), zeolites (Corma et al., 1990; Corma and Martin-Aranda, 1993; Reddy and Verma, 1997; Joshi et al., 2003), and clays (Bigi et al., 1999). Heterogeneous catalysts provide number of advantages (they are easily recoverable, reusable and minimize the undesired wastes) over homogeneous ones but most examples of Knoevenagel condensation over solid catalysts are related to baseactivated processes. Since that, comparative investigation of acid catalysts in Knoevenagel condensation seems topical.

Pechmann condensation is a reaction of phenols with beta-ketonic esters or unsaturated carboxylic acids (Scheme 2) resulting in the formation of coumarins-important natural substances with broad applications in pharmaceutical, agrochemical, and fragrance industries (Weinmann, 1997). Pechmann reaction was carried out in the presence of concentrated $\mathrm{H}_{2} \mathrm{SO}_{4}$ (Russell and Frye, 1955), $\mathrm{CF}_{3} \mathrm{COOH}$ (Woods and Sapp, 1962), $\mathrm{P}_{2} \mathrm{O}_{5}$ (Canter et al., 1931), $\mathrm{AlCl}_{3}$ (Das Gupta et al., 1969). During the last decade, zeolites (Hoefnagel et al., 1995), amberlyst (Sabou et al., 2005), montmorillonite K 10 (Li et al., 1998), heteropolyacids (Torviso et al., 2008), functionalized mesoporous silica [e.g., Zr-TMS (Torviso et al., 2008), Al-MCM-41 (Sudha et al., 2008), SBA-15-Ph-Pr-SO ${ }_{3} \mathrm{H}$ (Karimi and Zareyee, 2008)], metal oxides (e.g., sulfated zirconia) (Tyagi et al., 2007), inorganic ion exchangers (Sabou et al., 2005), and superacid-functionalized mesoporous materials (Kalita et al., 2010) have also been employed to catalyze Pechmann condensation.

Prins reaction, involving the electrophilic addition of an activated paraformaldehyde ( $\mathrm{PF}$ ) to $\beta$-pinene, leads to the formation of nopol (6,6-dimethylbicyclo[3.1.1] hept-2-ene-2-ethanol), an optically active bicyclic primary alcohol, useful in the agrochemical industry to produce pesticides, soap perfumes, detergents and polishes (Bledsoe, 1997) (Scheme 3). Hydrochloric acid, alkylsubstituted aluminum chlorides (Williams et al., 2002), $\mathrm{SnCl}_{4}$ (Andersen et al., 1985), $\mathrm{InCl}_{3}$ (Yadav et al., 2003), and heteropolyacids ( $\mathrm{Li}$ et al., 2004) are typically used to catalyze Prins reaction in homogeneous systems. Several heterogeneous catalytic systems have also been reported for Prins condensation of $\beta$-pinene with formaldehyde, including mesoporous iron phosphate (Pillai and Sahle-Demessie, 2004), Fe-Zn double cyanide (Patil et al., 2007), metal supported (Zn-, Al- and Sn-) MCM41 mesoporous molecular sieves (de Villa and Alarcon, 2002; Corma and Renz, 2007; Alarcon et al., 2010; Selvaraj and Sinha, 2010), $\mathrm{SnCl}_{4}$ grafted on MCM-41 (de Villa et al., 2005), $\mathrm{ZnCl}_{2}$ 


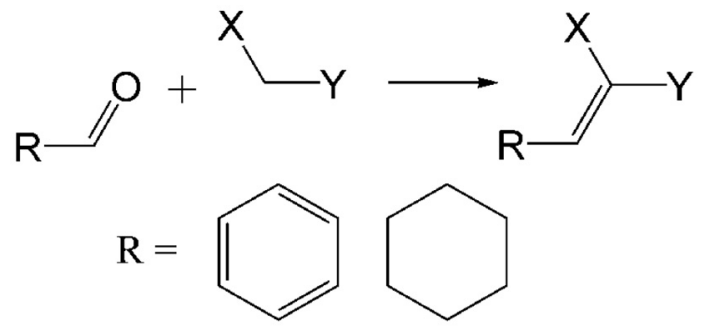

$\mathrm{X}, \mathrm{Y}=-\mathrm{C}(\mathrm{O}) \mathrm{CH}_{3} \quad-\mathrm{CN} \quad-\mathrm{COOAlk}$

SCHEME 1 | Schematic representation of Knoevenagel condensation.

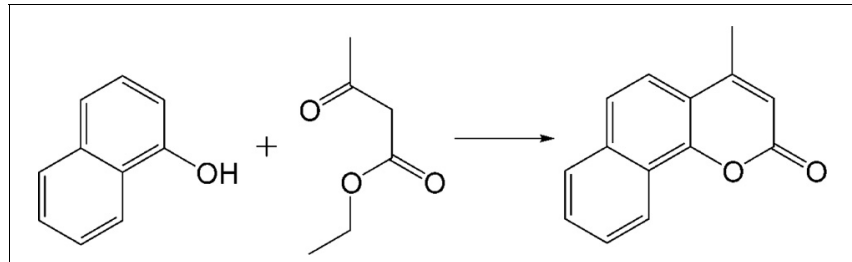

SCHEME 2 | Schematic representation of Pechmann condensation of 1-naphthol and ethyl acetoacetate.

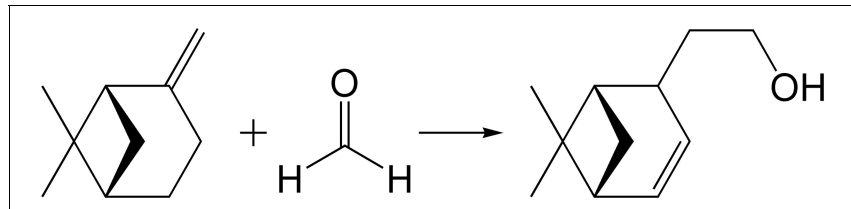

SCHEME 3 | Prins reaction of $\beta$-pinene with formaldehyde.

impregnated on Montmorillonite (Yadav and Jasra, 2006), and Sn-SBA-15 (Selvaraj and Choe, 2010). However, doping of metals into mesoporous silica does not produce single site catalysts and due to the amorphous nature, metal-doped mesoporous materials are not stable enough due to a leaching of the active phase.

Due to extra-high porosity (Chae et al., 2004), the regular arrangement of a large number of active sites and mostly Lewis acidity metal-organic frameworks (MOFs) attract significant attention as perspective heterogeneous catalysts, which are able to compete with the traditionally used zeolites ( $\mathrm{Li}$ et al., 1999; Eddaoudi et al., 2002; Chae et al., 2004; Corma et al., 2010; Dhakshinamoorthy et al., 2013). MOFs exhibit a high catalytic activity in Knoevenagel condensation reactions (Opanasenko et al., 2013a) and perform even better in transformations of bulky substrates than zeolites due to steric limitations. At the same time, other condensation reactions have been considerably less explored over MOFs (Opanasenko et al., 2013b).

Extra-large pore zeolites, possessing micropores larger than $0.85 \mathrm{~nm}$, represent another group of porous materials with a great potential for application in fine chemistry catalysis (Jiang et al., 2010). Zeolite UTL (Corma et al., 2004; Paillaud et al., 2004; Shvets et al., 2008), containing two-dimensional system of intersecting large (12-rings) and extra-large channels (14-rings) with dimensions $0.85 \times 0.55 \mathrm{~nm}$ and $0.95 \times 0.71 \mathrm{~nm}$, belongs to the thermally stable extra-large pore zeolites. Moreover, the catalytic activity of (Al)UTL was shown to be higher with respect to UTD-1 zeolite, having one-dimensional 14-ring channel system, in dealkylation of tri-isopropylbenzene and di-isopropylbenzene (Corma et al., 2004). Recently, higher activity and selectivity of Al-substituted UTL zeolites in acylation of p-xylene with benzoyl chloride in comparison to large-pore alumosilicate zeolite beta was shown (Shamzhy et al., 2013). However, despite extra-large pore zeolite UTL looks like promising solid catalyst for the liquid phase condensation reactions (i.e., Knoevenagel, Pechmann), as far as we know, there are no reports addressing this issue.

Our contribution is aimed at the investigation of catalytic properties of some zeolites and metal-organic-frameworks, in particular in comparison of B-, Al-, Ga-, Fe-substituted extralarge-pore zeolites UTL with large-pore alumosilicate zeolite (Al)beta and MOFs $\left[\mathrm{Cu}_{3}(\mathrm{BTC})_{2}, \mathrm{Fe}(\mathrm{BTC})\right]$ in Knoevenagel, Pechmann, and Prins reactions. The selection of (Al)beta, $\mathrm{Cu}_{3}$ (BTC) $)_{2}$ and $\mathrm{Fe}$ (BTC) as the reference materials was made based on their wide availability and ample use as solid catalysts.

\section{EXPERIMENTAL SECTION MATERIALS AND METHODS}

1-naphthol ( $\geq 98.0 \%)$, cyclohexane carbaldehyde (97\%), benzaldehyde $(\geq 99.0 \%)$, ethyl acetoacetate $(\geq 99.0 \%)$, $\beta$-pinene $(99 \%)$ and PF (95\%) were used as substrates, n-dodecane $(\geq 99 \%)$ and mesitylene $(\geq 99 \%)$-as internal standards, nitrobenzene (99\%), p-xylene $(\geq 99 \%)$ and acetonitrile (99.8\%)—as solvents in catalytic experiments. 2-ethylpiperidine $(\geq 98.0 \%)$, 1,5-dibromopentane $(\geq 98.0 \%)$, chloroform $(\geq 99.0 \%)$, diethyl ether $(\geq 99.0 \%)$, sodium sulfate anhydrous $(\geq 99.0 \%)$ were used for the synthesis of structure directing agent. Boric acid $(\geq 99.0 \%)$, aluminum hydroxide (reagent grade), iron(III) nitrate nonahydrate ( $\geq 98.0 \%)$, gallium(III) nitrate hydrate (99.9\%), germanium(IV) oxide (99.9\%), Cab-O-Sil M5 were used for the synthesis of UTL zeolites.

All reactants and solvents were obtained from Sigma Aldrich and used as received without any further treatment.

Ion-exchange resin AG 1-X8 was obtained from Bio-Rad.

\section{SYNTHESIS OF TEMPLATES AND CATALYSTS}

Preparation of 7-ethyl-6-azoniaspiro[5.5] undecane hydroxide was carried out using a method similar to Refs. (Shvets et al., 2010, 2011). The detailed description of the synthesis of UTL zeolites can be found in refs. (Shvets et al., 2010, 2011; Shamzhy et al., 2012). Zeolite (Al)beta was obtained from zeolyst in $\mathrm{NH}_{4}$-form and calcined at $450^{\circ} \mathrm{C}$ for $4 \mathrm{~h}$ prior to use.

$\mathrm{Cu}_{3}(\mathrm{BTC})_{2}$ (Basolite C300) and Fe(BTC) (Basolite F300) were provided by Sigma Aldrich.

\section{CHARACTERIZATION}

The crystallinity of samples under study was determined by X-ray powder diffraction on a Bruker AXS D8 Advance diffractometer 
with a Vantec-1 detector in the Bragg-Brentano geometry using $\mathrm{CuK} \alpha$ radiation. To limit the effect of preferential orientation of individual crystals a gentle grinding of the samples was performed before measurements.

Adsorption isotherms of nitrogen at $-196^{\circ} \mathrm{C}$ were determined using an ASAP 2020 (Micromeritics) static volumetric apparatus. In order to attain sufficient accuracy in the accumulation of the adsorption data, the ASAP 2020 was equipped with pressure transducers covering the $133 \mathrm{~Pa}, 1.33 \mathrm{kPa}$ and $133 \mathrm{kPa}$ ranges. Before adsorption experiments the samples were outgassed under turbomolecular pump vacuum at temperature of $150^{\circ} \mathrm{C}$ for MOFs and $250^{\circ} \mathrm{C}$ for zeolites. This temperature was maintained for $8 \mathrm{~h}$.

The concentrations of Brønsted and Lewis acid sites in zeolites were determined by pyridine adsorption at $150^{\circ} \mathrm{C}$ followed by FTIR spectroscopy (Nicolet 6700) using self-supporting wafer technique. Generally, a thin sample wafer of zeolite was activated prior to the experiment in a high vacuum $\left(10^{-4}\right.$ Torr $)$ at $450^{\circ} \mathrm{C}$ overnight. Adsorption of pyridine proceeded at room temperature for $30 \mathrm{~min}$ at a partial pressure of 5 Torr and was followed by $20 \mathrm{~min}$ evacuation at the temperature $150^{\circ} \mathrm{C}$. For the quantitative determination of concentration of relevant acid sites the molar adsorption coefficients (Emeis, 1993) for pyridine adsorbed on Brønsted $\left[\nu(C=N)-B\right.$ at $1540 \mathrm{~cm}^{-1}, \varepsilon(\mathrm{Br})=$ $1.67 \mathrm{~cm} / \mu \mathrm{mol}]$ and Lewis acid sites $\left[\nu(C=N)-\mathrm{L}\right.$ at $1470 \mathrm{~cm}^{-1}$, $\varepsilon(\mathrm{L})=2.22 \mathrm{~cm} / \mu \mathrm{mol}]$ were used. Determination of Lewis acid sites in CuBTC is discussed in detail elsewhere (Pérez-Mayoral et al., 2012).

\section{CATALYSIS}

The condensation reactions were performed in a liquid phase under atmospheric pressure in a multi-experiment work station StarFish (Radley's Discovery Technologies UK). Prior to use, $200 \mathrm{mg}$ of the catalyst was activated at $150^{\circ} \mathrm{C}$ (for MOFs) or $450^{\circ} \mathrm{C}$ (for zeolites) for $90 \mathrm{~min}$ with a temperature rate $10^{\circ} \mathrm{C} / \mathrm{min}$ in a stream of air.

\section{Pechmann condensation}

Typically, $8.5 \mathrm{mmol}$ of 1-naphthol, $0.5 \mathrm{~g}$ of $\mathrm{n}$-dodecane (internal standard), $10 \mathrm{ml}$ of nitrobenzene and $200 \mathrm{mg}$ of catalyst were added to the 3-necked vessel, equipped with condenser and thermometer, stirred, and heated. $100 \mathrm{mmol}$ of ethyl acetoacetate was added into the reaction vessel through a syringe when the temperature of $130^{\circ} \mathrm{C}$ was reached.

\section{Knoevenagel condensation}

Typically, $6.0 \mathrm{mmol}$ of aldehyde, $0.4 \mathrm{~g}$ of mesitylene (internal standard), $10 \mathrm{ml}$ of p-xylene and $200 \mathrm{mg}$ of catalyst were added to the 3-necked vessel, equipped with condenser and thermometer, stirred, and heated. $9.0 \mathrm{mmol}$ of ethyl acetoacetate was added into the reaction vessel through a syringe when the temperature of $130^{\circ} \mathrm{C}$ was reached.

\section{Prins condensation}

Typically, $8.0 \mathrm{mmol}$ of PF, $0.4 \mathrm{~g}$ of mesitylene (internal standard), $10 \mathrm{ml}$ of acetonitrile and $200 \mathrm{mg}$ of catalyst were added to the 3necked vessel, equipped with a condenser and a thermometer, stirred, and heated. $4.0 \mathrm{mmol}$ of $\beta$-pinene was added into the reaction vessel through a syringe when the temperature of $80^{\circ} \mathrm{C}$ was reached.

Aliquots of the reaction mixture were sampled at the interval time of $0,20,60,120,180,240,300,360 \mathrm{~min}$ in order to determine the equilibrium of the reaction. Zero point of conversion corresponds to the concentration of phenol, aldehyde, or $\beta$-pinene in starting solution in the presence of catalyst (to neglect the contribution of adsorption).

To evaluate a potential influence of leaching of active species from the heterogeneous catalysts, a part of the reaction mixture was filtered at the reaction temperature and the obtained liquid phase was further investigated in condensation reaction under the same reaction conditions.

\section{Reaction product analysis}

The reaction products were analyzed by gas chromatography (GC) using an Agilent 6850 with FID detector equipped with a non-polar HP1 column (diameter $0.25 \mathrm{~mm}$, thickness $0.2 \mu \mathrm{m}$ and length $30 \mathrm{~m}$ ). Reaction products were indentified using GC-MS analysis (ThermoFinnigan, FOCUS DSQ II Single Quadrupole GC/MS).

\section{RESULTS AND DISCUSSION CHARACTERISTICS OF THE CATALYSTS}

The X-ray diffraction patterns of all the catalysts match well with those reported in the literature (Figure A1) (Chui et al., 1999; Shvets et al., 2008; Dhakshinamoorthy et al., 2012).

While (Al)beta, (B), (Al), (Ga), (Fe)UTL and $\mathrm{Cu}_{3}(\mathrm{BTC})_{2}$ were found to be highly crystalline, $\mathrm{Fe}(\mathrm{BTC})$ represents less ordered material.

The known frameworks of the catalysts under investigation are depicted on Figure 1. In $\mathrm{Cu}_{3}(\mathrm{BTC})_{2}$ framework, the $\mathrm{Cu}^{2}$ clusters are coordinated via carboxylate groups of benzene-1,3,5tricarboxylate to form a paddlewheel unit in a three-dimensional porous cubic network (Figure 1A). Zeolite beta consists of an intergrowth of two distinct structures termed polymorphs A (Figure 1B) and B. The polymorphs grow as two-dimensional sheets and the sheets randomly alternate. Both polymorphs have a three dimensional network of 12-ring pores $(0.64 \times 0.76$ and $0.56 \times 0.56 \mathrm{~nm})$. The intergrowth of the polymorphs does not significantly affect the pores in two of the dimensions, but in the direction of the faulting, the pore becomes tortuous, but not blocked. Zeolite UTL (Figure 1C) belongs to the extra-large pore zeolites having $2 \mathrm{D}$ pore system of intersecting $14-(0.71 \times$ $0.95 \mathrm{~nm})$ and 12-ring channels $(0.85 \times 0.55 \mathrm{~nm})$.

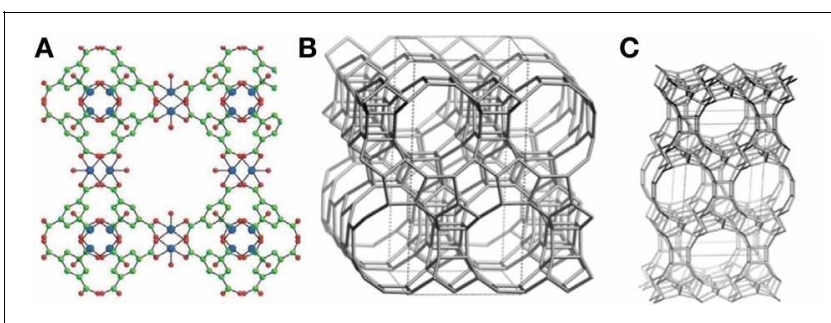

FIGURE 1 | Frameworks of $\mathrm{Cu}_{3}(\mathrm{BTC})_{2}$ (A), beta (B), UTL (C). 

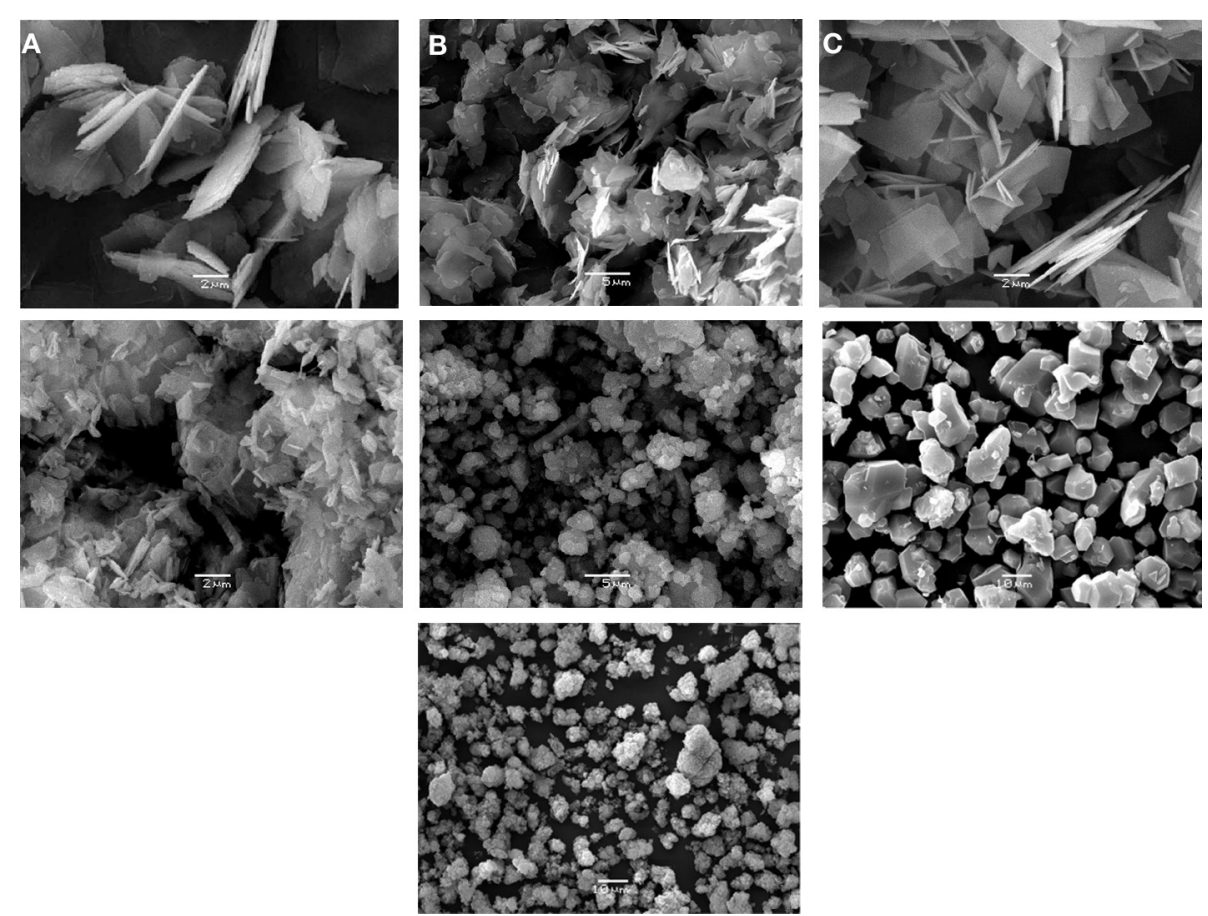

FIGURE 2 | SEM images of the catalysts. (A) (B)UTL, (B) (AI)UTL, (C) (Ga)UTL, (D) (Fe)UTL, (E) (Al)beta, (F) $\mathrm{Cu}_{3}(\mathrm{BTC})_{2},(\mathbf{G}) \mathrm{Fe}(\mathrm{BTC})$.

Table 1 | Textural properties of the catalysts.

\begin{tabular}{|c|c|c|c|c|}
\hline Catalyst & Crystal size $\mathrm{e}^{[\mathrm{a}]}, \mu \mathrm{m}$ & $\begin{array}{l}S_{\mathrm{BET}^{[\mathrm{b}]}}, \\
\mathrm{m}^{2} / \mathrm{g}\end{array}$ & $\begin{array}{l}D_{\text {micro }}^{[b]}, \\
\text { nm }\end{array}$ & $\begin{array}{l}V_{\text {micro }}^{[\mathrm{b}]}, \\
\mathrm{cm}^{3} / \mathrm{g}\end{array}$ \\
\hline $\mathrm{Cu}_{3}(\mathrm{BTC})_{2}$ & 7 & 1500 & 0.90 & 0.64 \\
\hline $\mathrm{Fe}(\mathrm{BTC})$ & 3 & 1060 & 0.86 & 0.33 \\
\hline (B)UTL & $6.0 \times 4.0 \times 0.2$ & 570 & 1.00 & 0.21 \\
\hline (Ga)UTL & $7.0 \times 5.0 \times 0.2$ & 450 & 1.00 & 0.17 \\
\hline (Fe)UTL & $6.0 \times 4.0 \times 0.5$ & 550 & 1.00 & 0.21 \\
\hline (AI)UTL & $4.0 \times 0.5 \times 0.1$ & 500 & 1.00 & 0.19 \\
\hline (Al)beta & 0.5 & 670 & 0.66 & 0.2 \\
\hline
\end{tabular}

${ }^{[a]}$ According to SEM images.

${ }^{[b]}$ According to adsorption/desorption isotherms of $\mathrm{N}_{2}$.

Crystals of UTL zeolites possess rectangular shape (Figure 2) and have the close size, except (Al)UTL (Table 1). Crystals of zeolite $(\mathrm{Al})$ beta are characterized by size about $0.5 \mu \mathrm{m}$. The crystals of $\mathrm{Cu}_{3}(\mathrm{BTC})_{2}$ are rectangular prisms with the length of the edges of about $7 \mu \mathrm{m}$, while the size of the crystals of $\mathrm{Fe}(\mathrm{BTC})$ is about $3 \mu \mathrm{m}$.

Nitrogen adsorption isotherms of the catalysts are depicted in Figure 3. All catalysts exhibit type I isotherm being characteristic for microporous solids. The presence of a hysteresis loop at $p>0.8$ on the isotherm of (Al)UTL is probably connected with an interparticle adsorption. Textural properties of all catalysts are summarized in Table 1.

Acidic properties of the catalysts (i.e., type and concentrations of acid sites) were analyzed using adsorption of pyridine followed

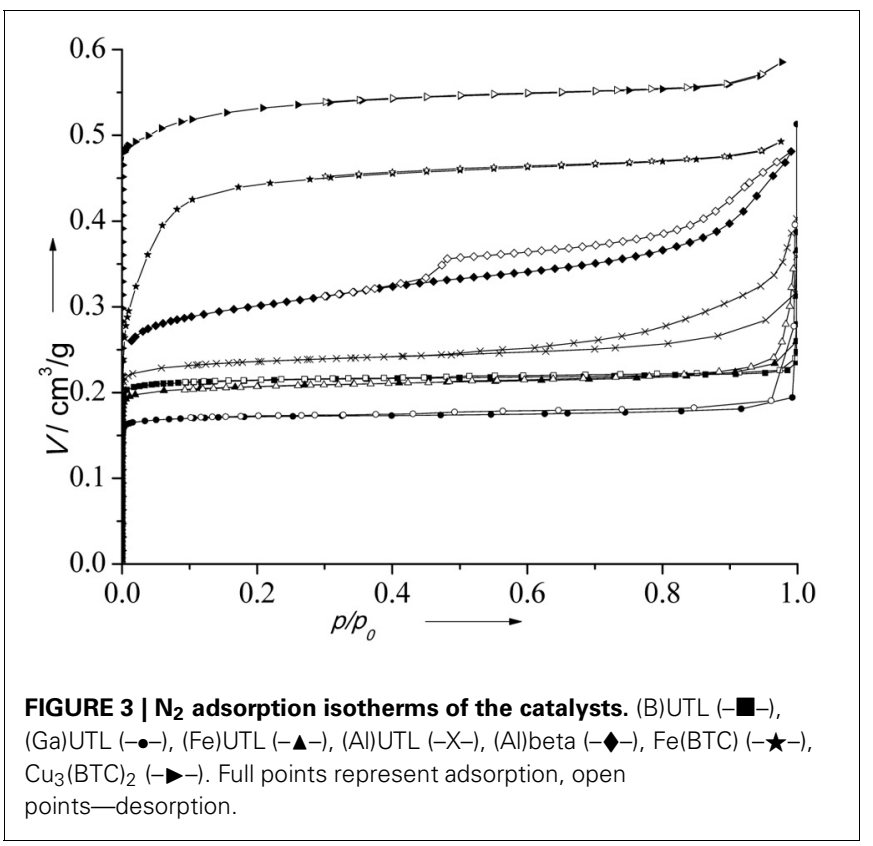

by FTIR. For zeolites, absorption bands around $1546 \mathrm{~cm}^{-1}$ (interaction of pyridine with Brønsted acid sites) and $1453-1455 \mathrm{~cm}^{-1}$ (interaction of pyridine with Lewis acid sites) were chosen as characteristic. To estimate the acidity of the $\mathrm{Cu}_{3}(\mathrm{BTC})_{2}$ band at $1069 \mathrm{~cm}^{-1}$ assigned to $\mathrm{C}-\mathrm{C}$ out-of-plane vibrations of coordinatively bonded pyridine was chosen (Pérez-Mayoral et al., 
2012). Characteristic bands in region $1400-1600 \mathrm{~cm}^{-1}$ were not used for the determination of the amount of acid sites in MOFs because of an overlap with the bands corresponding to MOF's framework.

Table 2 lists the concentrations of Brønsted and Lewis acid sites for different temperatures of pyridine desorption.

It can be seen, that the concentration of acid sites increases in the following sequence: $(\mathrm{B})<(\mathrm{Fe})<(\mathrm{Ga})<(\mathrm{Al}) \mathrm{UTL}<<$ (Al)beta. The concentration of coordinatively bonded pyridine was determined to be equal to $2.30 \mathrm{mmol} \mathrm{g}^{-1}$ for $\mathrm{Cu}_{3}$ (BTC) 2 activated at $200^{\circ} \mathrm{C}$ (Pérez-Mayoral et al., 2012).

\section{KNOEVENAGEL CONDENSATION}

The catalytic performance of MOFs and isomorphously substituted extra-large pore zeolites UTL was studied in Knoevenagel condensation of cyclohexane carbaldehyde (ChCA) and benzaldehyde (BA) with ethylacetoacetate (EAA) and compared with large-pore alumosilicate zeolite $(\mathrm{Al})$ beta.

Ethyl 2-(cyclohexylmethylene)-3-oxobutanoate (product I) and diethyl 2,4-diacetyl-3-cyclohexylpentanedioate (product II) were detected as the main products of Knoevenagel condensation of ChCA with EAA by GC-MS (Scheme 4) while ethyl

Table 2 | Acid properties of the catalysts.

\begin{tabular}{|c|c|c|c|c|c|}
\hline \multirow[t]{2}{*}{ Catalyst } & \multirow[t]{2}{*}{ 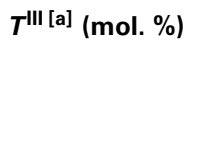 } & \multirow[t]{2}{*}{$T^{\mathrm{IV}} / T^{\mathrm{III}}$} & \multicolumn{3}{|c|}{ IR } \\
\hline & & & $\begin{array}{l}T_{\text {des }} . \\
\left({ }^{\circ} \mathrm{C}\right)\end{array}$ & $\begin{array}{l}\text { Brønsted, } \\
(\mu \mathrm{mol} / \mathrm{g} \text { ) }\end{array}$ & $\begin{array}{l}\text { Lewis, } \\
\text { ( } \mu \mathrm{mol} / \mathrm{g})\end{array}$ \\
\hline \multirow[t]{4}{*}{ (B)-UTL } & 0.5 & 199 & 150 & 15 & 60 \\
\hline & & & 250 & 15 & 41 \\
\hline & & & 350 & 0 & 0 \\
\hline & & & 450 & 0 & 0 \\
\hline \multirow[t]{4}{*}{ (Ga)UTL } & 1.4 & 70 & 150 & 23 & 64 \\
\hline & & & 250 & 21 & 62 \\
\hline & & & 350 & 14 & 57 \\
\hline & & & 450 & 6 & 61 \\
\hline \multirow[t]{4}{*}{ (Fe)UTL } & 5.9 & 16 & 150 & 36 & 97 \\
\hline & & & 250 & 19 & 35 \\
\hline & & & 350 & 12 & 31 \\
\hline & & & 450 & 7 & 22 \\
\hline \multirow[t]{4}{*}{ (AI)UTL } & 2.1 & 47 & 150 & 69 & 61 \\
\hline & & & 250 & 49 & 48 \\
\hline & & & 350 & 31 & 44 \\
\hline & & & 450 & 20 & 41 \\
\hline \multirow[t]{4}{*}{ (Al)beta } & 7.4 & 12.5 & 150 & 210 & 320 \\
\hline & & & 250 & 180 & 240 \\
\hline & & & 350 & 120 & 220 \\
\hline & & & 450 & 50 & 180 \\
\hline $\mathrm{Cu}_{3}(\mathrm{BTC})_{2}$ & - & - & - & - & 2300 \\
\hline
\end{tabular}

2-benzylidene-3-oxobutanoate (product III), benzoic acid (product IV) and 4-phenylbut-3-en-2-one (product V) were found in the case of benzaldehyde (BA) condensation (Scheme 5).

The conversion of aldehydes increased over UTL zeolites in the following sequence: $(\mathrm{B})<(\mathrm{Fe})<(\mathrm{Ga})<(\mathrm{Al}) \mathrm{UTL}$ (Figures 4A, 5A) matching well with the increasing concentration of accessible acid sites and particularly their acid strength. At the same time, while $\mathrm{Fe}-, \mathrm{Ga}$ - and Al-substituted UTL zeolites appeared to be low-selective catalyst (Figure 4B) in condensation of ChCA with EAA (11.9 and $8 \%$ selectivity to product I, respectively), the selectivity $46 \%$ of ether I was achieved when using B-containing UTL zeolite as the catalyst. This is most probably related to the acceleration of the rate of secondary reactions, involving the primary product $\mathrm{I}$, with increasing the concentration of acid sites in the range $(\mathrm{B})<(\mathrm{Fe}) \approx(\mathrm{Ga})<(\mathrm{Al}) \mathrm{UTL}$.

The initial conversions of ChCA in condensation reaction with EAA over (Al)beta and (Al)UTL were quite similar $(23 \%$ at 60 min TOS, Figure 4A). With increasing TOS the slope of the curve "conversion-TOS" became flatter for (Al)beta indicating

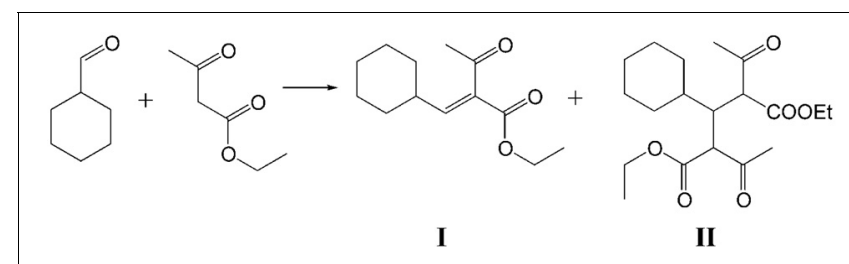

SCHEME 4 | Condensation of ChCA with EAA.
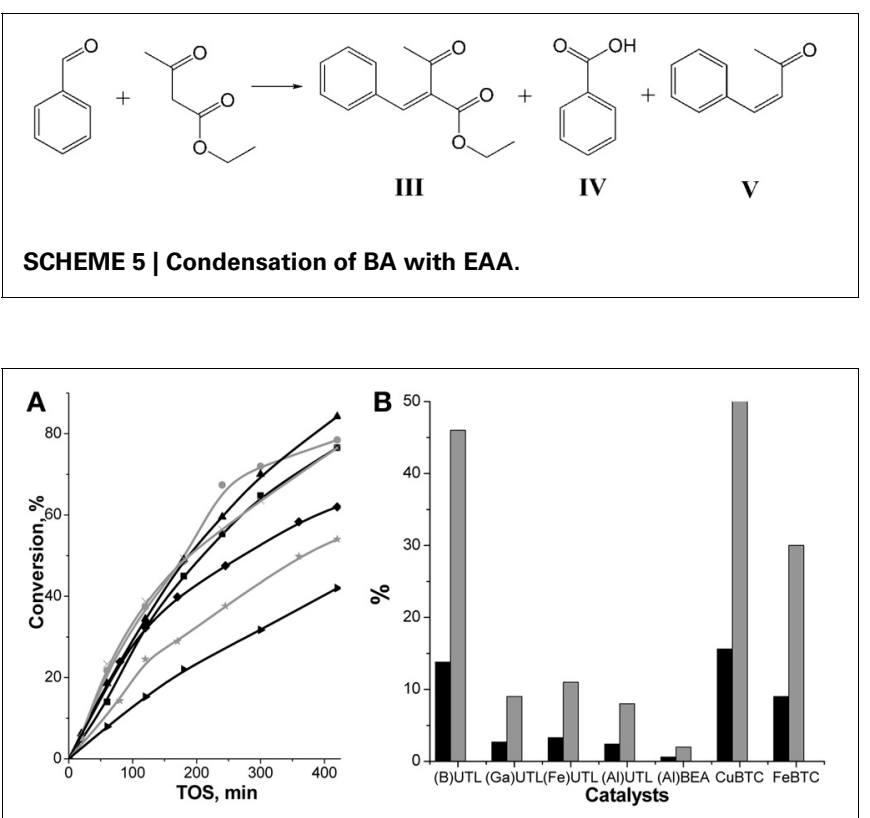

FIGURE 4 | TOS dependence of ChCA conversion in condensation reaction with EAA over (B)UTL (-口-), (Ga)UTL $(-\bullet-)$, (Fe)UTL (-A-), (AI)UTL (-X-), (AI)beta (- $\rightarrow-)$, Fe(BTC) (- $\star-), \mathrm{Cu}_{3}(\mathrm{BTC})_{2}(-\rightarrow-)$ (A); the yield ( $\square$ ) and selectivity ( $\square$ ) (at $30 \%$ of ChCA conversion) to the product I (B). 


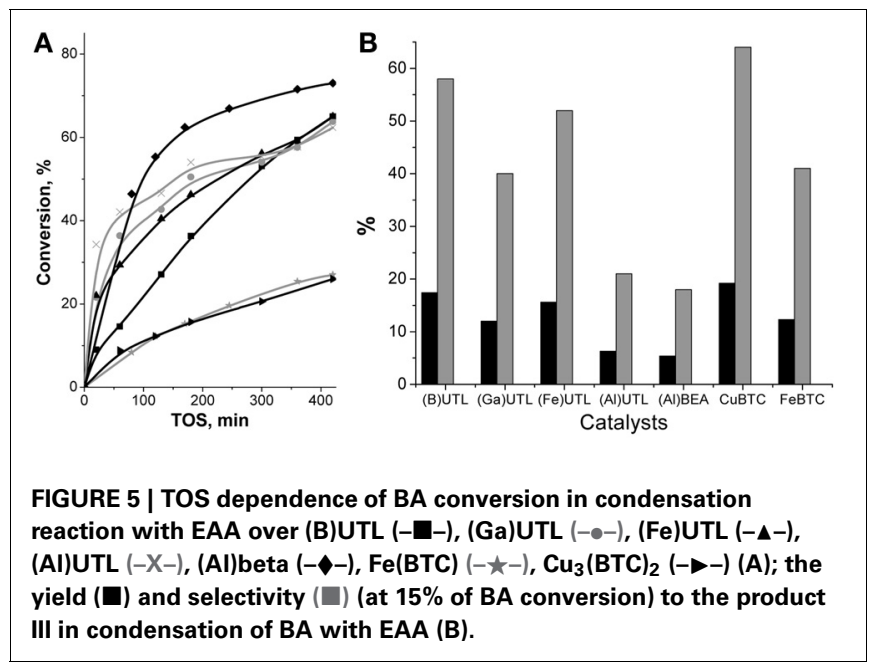

a lowering of the reaction rate. It may be caused by diffusion restrictions for substrates/products in the porous system of zeolite beta in comparison with extra-large pore zeolite UTL despite the crystal size of $(\mathrm{Al})$ beta is much more lower in comparison with $(\mathrm{Al}) \mathrm{UTL}(0.5 \times 0.5 \times 0.5$ vs. $4.0 \times 0.5 \times 0.1 \mu \mathrm{m}$, Table 1$)$. Moreover, the selectivity of $(\mathrm{Al})$ beta possessing the highest concentration of strong acid sites, reached expectedly the lowest value (2\%) among the investigated catalysts (Figure 4B).

Surprisingly, the lowest conversion of ChCA was found for $\mathrm{Cu}_{3}(\mathrm{BTC})_{2}$ (Figure 4A), possessing comparably high concentration of mild Lewis acid sites (Table 2). This may be due to the relative weakness of the respective tetracoordinated $\mathrm{Cu}^{2+}$ sites within the MOF for the activation of ChCA. However, $\mathrm{Cu}_{3}(\mathrm{BTC})_{2}$ demonstrated higher selectivity to the product $\mathbf{I}$ in comparison with UTL zeolites (52\%, Figure 4B), which may be also caused by low strength of acid sites within $\mathrm{Cu}_{3}(\mathrm{BTC})_{2}$.

When compared with ChCA, BA appeared to be easier activated substrate- the conversions of BA over all investigated catalysts were comparable or exceeded the respective values for ChCA (Figures 4A, 5A).

At the same time the increasing selectivity of the catalysts in the case of BA condensation with EAA may be caused by the electronwithdrawing effect of phenyl-group. It results in decreasing reactivity of the primary product III (Scheme 5) in the secondary reactions of Michael addition in comparison with the product I being transformed to product II (Scheme 4) over all investigated catalyst. Even though, Al-substituted zeolites beta and UTL were characterized by the lowest selectivity (20\%, Figure 5B) due to a rapid hydrolysis of the target ether III on strong Brønsted acid sites followed by dicarboxylation with the formation of sideproduct IV (Scheme 5). At the same time, the product of BA oxidation-benzoic acid was found as the side product when using (B)UTL, $\mathrm{Cu}_{3}(\mathrm{BTC})_{2}, \mathrm{Fe}(\mathrm{BTC})$, which appeared to be the most selective among the investigated ones.

The yields of the target products in Knoevenagel condensation of both ChCA and BA with EAA over the catalysts under investigation increase in the following sequence: (Al)beta $<(\mathrm{Al}) \mathrm{UTL}<$ (Ga)UTL $<(\mathrm{Fe}) \mathrm{UTL}<\mathrm{Fe}(\mathrm{BTC})<(\mathrm{B}) \mathrm{UTL}<\mathrm{Cu}_{3}(\mathrm{BTC})_{2}$, which is caused by the enhancement of the catalyst's selectivity with
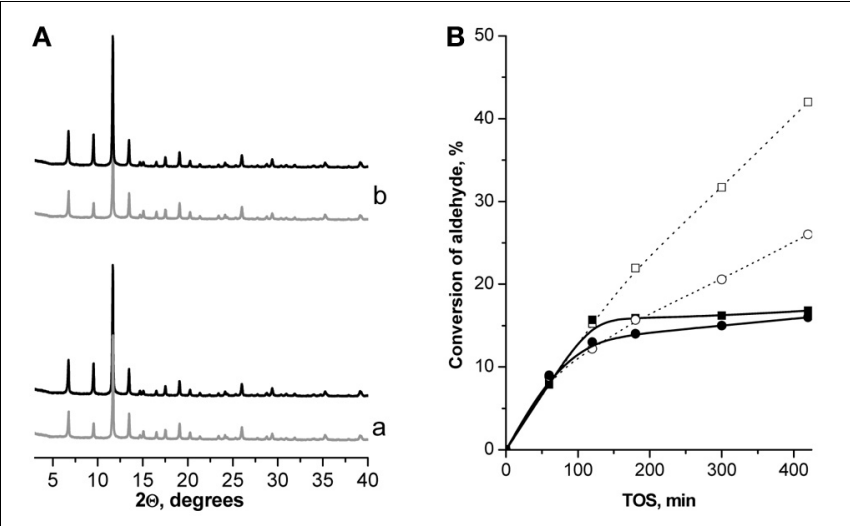

FIGURE 6 | XRD patterns of $\mathrm{Cu}_{3}(\mathrm{BTC})_{2}$ before (-) and after (-) $24 \mathrm{~h}$ TOS in Knoevenagel condensation of ChCA (a) and BA (b) with EAA at $130^{\circ} \mathrm{C}(\mathrm{A})$; leaching test: TOS dependence of the conversion of ChCA $(-\square-)$ and BA (-๑-) in Knoevenagel condensation with EAA (full line-leaching test, dotted line-standard experiment, $\left.T=130^{\circ} \mathrm{C}\right)(\mathrm{B})$.

the decreasing of the strength of active sites. The most active $\mathrm{Cu}_{3}(\mathrm{BTC})_{2}$ catalyst was proved to be structurally stable upon liquid phase Knoevenagel condensation with EAA at $130^{\circ} \mathrm{C}$ when using p-xylene as the solvent (Figure 6A). In addition, a negligible increase in the conversion of initial aldehydes after removing of $\mathrm{Cu}_{3}(\mathrm{BTC})_{2}$ from the "hot" reaction mixture at 120 min TOS confirms the absence of homogeneous reaction contribution, which might be caused by the leaching of active sites to the liquid phase (Figure 6B).

Despite Knoevenagel reaction can be catalyzed by both solid acids (activation of carbonyl component) and bases (activation of methylene component) (Tietze and Beifuss, 1991), it was mainly tested over basic catalysts. In ref. (Lau et al., 2008), Knoevenagel condensation of BA and EAA was performed in a microreactor using $\mathrm{Cs}$-exchanged $\mathrm{NaA}$ membrane and $\mathrm{NaX}$ crystals. It was shown that the using catalyst film instead of powder results in suppression of undesirable side-reactions (increasing the selectivity from 55 to $78 \%$ ) due to the rapid elaboration of Knoevenagel adduct from the porous system of the catalyst. Analogously, poor selectivity of (Al)beta in comparison with (Al)UTL may be caused by diffusional restrictions for the removal of the product from the porous system of the first catalyst. The influence of the strength of basic sites on the activity of Li-, Na-, K-, Rb-, Cs-impregnated simple oxide matrices $\left(\mathrm{SiO}_{2}, \mathrm{Al}_{2} \mathrm{O}_{3}, \mathrm{Nb}_{2} \mathrm{O}_{5}\right)$ was established (Calvino-Casilda et al., 2009). The best performance of $\mathrm{K} / \mathrm{Al}_{2} \mathrm{O}_{3}$ in Knoevenagel condensation of BA and EAA ( $90 \%$ of BA conversion and $89.8 \%$ of selectivity at $140^{\circ} \mathrm{C}$ in $300 \mathrm{~min}$ of TOS) was connected with the mild strength of basic sites, found for this system (Calvino-Casilda et al., 2009). Analogously, in the range of $\mathrm{Nb}-\mathrm{MCM}-41$ catalysts, impregnated by alkali metals, $\mathrm{Rb} / \mathrm{Nb}$ MCM-41 demonstrated the best performance ( $80 \%$ of benzaldehyde conversion in $4 \mathrm{~h}$ of TOS at $140^{\circ} \mathrm{C}$ ) (Calvino-Casilda et al., 2010).

\section{PECHMANN CONDENSATION}

Pechmann condensation of 1-naphthol proceeds according to the Scheme 2 with the formation of 4-methyl-2H-benzo[h] 


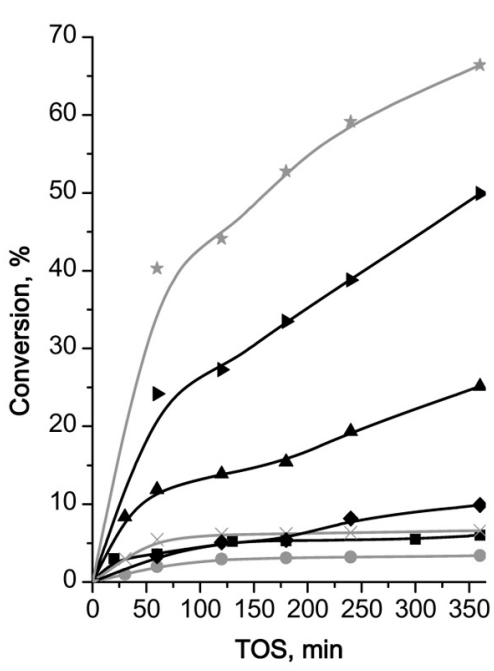

FIGURE 7 | TOS dependence of conversion of 1-naphthol in Pechmann condensation reaction with EAA over (B)UTL (-口-), (Ga)UTL (-๑-),

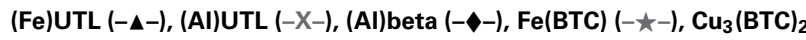
$(\rightarrow-)$.

chromen-2-one (Figure A2) as the target product and some unidentified polycondensation products.

Superiority of MOFs over large-pore zeolite (Al)beta and extra-large pore zeolite UTL in Pechmann condensation of 1naphthol was observed. While the conversion of the initial substrate at $120 \mathrm{~min}$ TOS did not exceed $15 \%$ for zeolites, it totaled 33 and $44 \%$ for $\mathrm{Cu}_{3}(\mathrm{BTC})_{2}$ and $\mathrm{Fe}(\mathrm{BTC})$, respectively (Figure 7). The selectivity to the target product was about $98 \%$ for both MOFs. A lower initial reaction rate over $\mathrm{Cu}_{3}(\mathrm{BTC})_{2}$ in comparison with $\mathrm{Fe}(\mathrm{BTC})$ may be caused by a lower accessibility of the active sites within $\mathrm{Cu}_{3}(\mathrm{BTC})_{2}$ catalyst, possessing smaller pore windows in comparison to $\mathrm{Fe}(\mathrm{BTC})$ (Table 1).

Higher conversion of 1-naphthol in Pechmann condensation over MOFs in comparison with zeolites may be connected with significantly higher concentration of acid sites of sufficient strength to activate the substrate. In addition, the facilitation of transport of both reagents and product within pore system of MOFs and extra-large pore UTL zeolites, most likely, prevents side-transformations resulting in 100\% selectivity to the target product of 1-naphthol condensation with EAA. Only $80 \%$ selectivity was observed when (Al)beta was used.

XRD patterns of $\mathrm{Cu}_{3}(\mathrm{BTC})_{2}$, elaborated from the reaction mixture after $24 \mathrm{~h}$ TOS, provide an evidence of the preservation of the framework of the MOF during the Pechmann condensation of 1-naphthol. At the same time no significant differences in the position of diffraction lines for the fresh and utilized $\mathrm{Fe}$ (BTC) were observed (Figure A3A).

Leaching test of the investigated MOFs removing them from the reaction mixture by "hot" centrifugation was not accompanied by the further increase in the conversion of 1-naphthol (Figure A3B), which strongly denies the leaching of the active sites for $\mathrm{Cu}_{3}(\mathrm{BTC})_{2}$ and $\mathrm{Fe}(\mathrm{BTC})$.
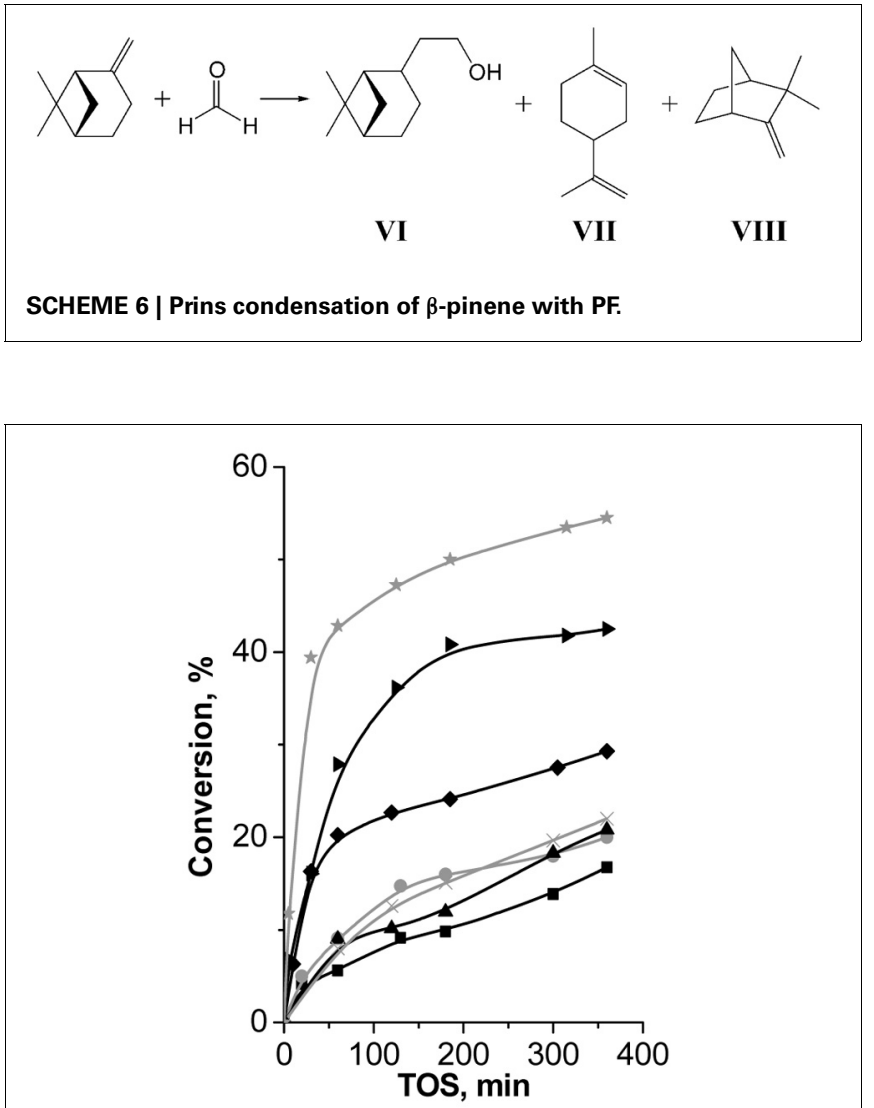

FIGURE 8 | TOS dependence of conversion of $\beta$-pinene in Prins reaction

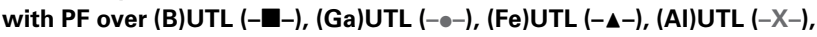
(AI)beta $(-\downarrow-)$, Fe(BTC) $(-\star-), \mathrm{Cu}_{3}(\mathrm{BTC})_{2}(->-)$.

It should be noted that catalytic activity of and FeBTC is comparable with periodic mesoporous silica chloride (the yield of target product $75 \%$ at $130^{\circ} \mathrm{C}$ and $180 \mathrm{~min}$ of TOS),(Karimi and Behzadnia, 2011) and SBA-15-Ph-Pr- $\mathrm{SO}_{3} \mathrm{H}$ (the yield of target product $65 \%$ at $130^{\circ} \mathrm{C}$ and $240 \mathrm{~min}$ of TOS) (Kalita et al., 2010), which were shown to be one of the most promising catalysts for Pechmann condensation of 1-naphthol.

\section{PRINS REACTION}

In the Prins reaction of $\beta$-pinene with formaldehyde besides the formation of target product nopol (VI) we observed also the formation of the side products of $\beta$-pinene isomerizationlimonene (VII) or camphene (VIII) (Scheme 6).

$\mathrm{Fe}$ (BTC) showed the highest performance (47\% of $\beta$-pinene conversion at $120 \mathrm{~min}$ of TOS, Figure 8) in Prins reaction of $\beta$-pinene with formaldehyde among the investigated catalysts and providing $100 \%$ selectivity to the target productnopol.

Both isomorphously substituted UTL and (Al)beta zeolites appeared to be less efficient catalysts in reaction of $\beta$-pinene with formaldehyde in comparison with $\mathrm{Fe}(\mathrm{BTC})$. It is obviously caused by the much lower concentration of active sites in zeolites (Table 2). The conversion of $\beta$-pinene increases for 
extra-large-pore UTL zeolites in the sequence: $(\mathrm{B})<(\mathrm{Fe})<$ $(\mathrm{Ga}) \approx(\mathrm{Al}) \mathrm{UTL}$ and does not exceed $15 \%$ in $120 \mathrm{~min}$ of TOS (Figure 8). The conversion of $\beta$-pinene over large-pore zeolite (Al)beta was higher than over UTL-based catalysts, which might be due to the higher concentration of active sites accessible for $\beta$-pinene (Table 2 ). In contrast to $\mathrm{Fe}(\mathrm{BTC})$, we observed the formation of side product VI over zeolite beta (40\% selectivity to nopol). This result shows that the presence of relatively strong Brønsted acid sites leads to the reduction of the catalyst performance in reaction of $\beta$-pinene with formaldehyde.

Surprisingly, only isomerization of initial substrate with the formation of camphene took place over $\mathrm{Cu}_{3}(\mathrm{BTC})_{2}$, which similarly to $\mathrm{Fe}(\mathrm{BTC})$ is characterized by the mild exclusively Lewis acidity and close size of micropores. The reasons of camphene formation are not entirely clear on the moment.

To check the possibility of leaching of $\mathrm{Fe}^{3+}$ ions from the framework to the solution, the most active Fe(BTC) catalyst was surveyed for leaching, which evidences a negligible increase in the conversion after removal by centrifugation of the solid catalyst from reaction mixture at $120 \mathrm{~min}$ of TOS, indicating that no leaching of the active species takes place (Figure A4).

Thus, Fe(BTC), containing the largest amount of acid sites of appropriate strength to activate initial $\beta$-pinene, overtops largepore zeolite (Al)beta and $\mathrm{B}-, \mathrm{Al}-, \mathrm{Ga}-, \mathrm{Fe}$-substituted extra-large pore zeolites UTL in Prins reaction of $\beta$-pinene with PF.

When compared our results with the previously obtained, montmorillonite impregnated with $\mathrm{ZnCl}_{2}$ prepared by wet impregnation technique was shown to be active in Prins reaction of $\beta$-pinene with PF (75\% of $\beta$-pinene conversion and $97 \%$ selectivity after $24 \mathrm{~h}$ TOS). However, leaching of $\mathrm{Zn}^{2+}$ took place, contributing into the overall conversion value (Yadav and Jasra, 2006). In (Selvaraj and Choe, 2010) Sn-doped SBA-15 was shown to be highly active catalyst for nopol synthesis via Prins reaction of $\beta$-pinene and PF. The activity of the catalyst increased with the increasing of the concentration of active tetracoordinated $\mathrm{Sn}^{4+}$ species. The best results ( $\beta$-pinene conversion of $99.3 \%$ and a

\section{REFERENCES}

Alarcon, E. A., Correa, L., Montes, C., and de Villa, A. L. (2010). Nopol production over Sn-MCM41 synthesized by different procedures - Solvent effects. Micropor. Mesopor. Mater. 136, 59-67. doi: 10.1016/j.micromeso.2010.07.021

Andersen, N. H., Hadley, S. W., Kelly, J. D., and Bacon, E. R. (1985). Intramolecular olefinic aldehyde Prins reactions for the construction of 5-membered rings. J. Org. Chem. 50, 4144-4151. doi: 10.1021/jo00221a034

Bartoli, G., Beleggia, R., Giuli, S., Giuliani, A., Marcantoni, E., Massaccesi, M., et al. (2006). The $\mathrm{CeCl}_{3} \cdot 7 \mathrm{H}_{2} \mathrm{O}-\mathrm{NaI}$ system as promoter in the synthesis of functionalized trisubstituted alkenes

nopol selectivity of $95.4 \%$ at 360 min of TOS) were achieved over Sn-SBA-15 ( $\mathrm{Si} / \mathrm{Sn}=5)$, which was characterized by the highest amount of Lewis acid centers.

\section{CONCLUSIONS}

Catalytic performance of extra-large pore germanosilicate UTL zeolites prepared by incorporation of different heteroelements (e.g., B, Al, Ga, Fe) into the framework in Knoevenagel, Pechmann, Prins reactions was investigated and compared with that of large-pore aluminosilicate zeolite beta and $\mathrm{Cu}-$, $\mathrm{Fe}$ containing metal-organic-frameworks.

The performance of UTL zeolites in Knoevenagel condensation is mainly determinated by the strength of acid sites. While the conversion of initial ChCA and BA matches with the total concentration of acid sites and increases in the following sequence $(B)<$ $(\mathrm{Fe})<(\mathrm{Ga})<(\mathrm{Al}) \mathrm{UTL}$, the selectivity of the catalysts depends on the strength of active centers and has the highest value for B-UTL, containing the weakest acid centers.

The yields of the target products in Knoevenagel condensation of both ChCA and BA with EAA over the catalysts under investigation increase in the following sequence: (Al)beta $<(\mathrm{Al}) \mathrm{UTL}<$ $(\mathrm{Ga}) \mathrm{UTL}<(\mathrm{Fe}) \mathrm{UTL}<\mathrm{Fe}(\mathrm{BTC})<(\mathrm{B}) \mathrm{UTL}<\mathrm{Cu}_{3}(\mathrm{BTC})_{2}$, which is caused by the enhancement of the catalyst selectivity with the decreasing of the strength of active sites.

$\mathrm{Fe}$ (BTC) surpasses not only large-pore zeolite (Al)beta, but also isomorphously substituted extra-large pore zeolites UTL in Pechmann condensation of 1-naphthol with EAA and Prins reaction of $\beta$-pinene with PF, which seems to be caused by the much more higher concentration of accessible active sites within MOF and their appropriate strength.

\section{ACKNOWLEDGMENTS}

The research leading to these results has received funding from the European Community's Seventh Framework Programme (FP7/2007-2013) under grant agreement no. 228862. Jiří Čejka thanks the Czech Grant Agency for financial support (Centre of Excellence-P106/12/G015).

Kroschwitz and M. Howe-Grant (New York, NY: Wiley), 833-882.

Borah, H. N., Deb, M. L., Boruah, R. C., and Bhuyan, P. J. (2005). Stereoselective intramolecular hetero Diels-Alder reactions of 1-oxa1, 3-butadienes: synthesis of novel annelated pyrrolo[1, 2-a]indoles. Tetrahedron Lett. 46, 3391-3393. doi: 10.1016/j.tetlet.2005.03.091

Calvino-Casilda, V., Martin-Aranda, R. M., Lopez-Peinado, A. J., Sobczak, I., and Ziolek, M. (2009). Catalytic properties of alkali metal-modified oxide supports for the Knoevenagel condensation: kinetic aspects. Catal. Tod. 142, 278-282. doi: 10.1016/j.cattod.2008.08.023

Calvino-Casilda, V., Pérez-Mayoral, E., Martín-Aranda, R. M., Zienkiewicz, Z., Sobczak, I., and Ziolek, M.
(2010). Isomerization of Eugenol under ultrasound activation catalyzed by alkali modified mesoporous NbMCM-41. Top. Catal. 53, 179-186. doi: 10.1007/s11244-0099422-y

Canter, F. W., Curd, F. H., and Robertson, A. (1931). Hydroxycarbonyl compounds. Part, I. I. I. The preparation of coumarines and 1 4-benzopyrones from phloroglucinol and resorcinol. J. Chem. Soc. 1, 1255-1265. doi: 10.1039/jr9310001255

Chae, H. K., Siberio-Perez, D. Y., Kim, J., Go, Y. B., Eddaoudi, M., Matzger, A. J., et al. (2004). A route to high surface area, porosity and inclusion of large molecules in crystals. Nature 427, 523-527. doi: 10.1038 /nature02311 
Chui, S. S. Y., Lo, S. M. F., Charmant, J. P. H., Orpen, A. G., and Williams, I. D. (1999). A chemically functionalizable nanoporous material [Cu-3(TMA)(2)(H2O)(3)] (n). Science 283, 1148-1150. doi: 10.1126/science.283.5405.1148

Corma, A., Díaz-Cabañas, M. J., and Rey, F. (2004). ITQ-15: the first ultralarge pore zeolite with a bidirectional pore system formed by intersecting 14- and 12-ring channels, and its catalytic implications. Chem. Commun. 40, 1356-1357. doi: 10.1039/b406572g

Corma, A., Fornes, V., Martin-Aranda, R. M., Garcia, H., and Primo, J. (1990). Zeolites as base catalysts: condensation of aldehydes with derivatives of malonic esters. Appl.Catal. 59, 237-248. doi: 10.1016/S0166-9834(00)82201-0

Corma, A., García, H., and Llabrés i Xamena, F. X. (2010). Engineering metal organic frameworks for heterogeneous catalysis. Chem. Rev. 110, 4606-4655. doi: $10.1021 / \mathrm{cr} 9003924$

Corma, A., and Martin-Aranda, R. M. (1993). Application of solid base catalysts in the preparation of prepolymers by condensation of ketones and malononitrile. Appl. Catal. A Gen. 105, 271-279. doi: 10.1016/0926-860X(93)80252-L

Corma, A., and Renz, M. (2007). Waterresistant Lewis-acid sites: carbonylene reactions catalyzed by tincontaining, hydrophobic molecular sieves. ARKIVOC 8, 40-48.

Das Gupta, A. K., Chatterje, R. M., Das, K. R., and Green, B. (1969). Coumarins and related compounds. 4. Aluminium chloride-catalysed reaction of phenols with methyl acrylate-a new approach to synthesis of hydroxycoumarins. J. Chem. Soc. C 1, 29-33. doi: 10.1039/j39690000029

de Villa, A. L., and Alarcon, P. E. (2002). Synthesis of nopol over MCM41 catalysts. Chem. Commun. 22, 2654-2655. doi: 10.1039/b206239a

de Villa, A. L., Alarcon, P. E., and de Monteas, C. (2005). Nopol synthesis over Sn-MCM-41 and Sn-kenyaite catalysts. Catal. Tod. 107-108, 942-948. doi: 10.1016/j.cattod.2005.07.049

Dhakshinamoorthy, A., Alvaro, M., Horcajada, P., Gibson, E., Vishnuvarthan, M., Vimont, A., et al. (2012). Comparison of porous iron trimesates Basolite F300 and MIL-100(Fe) as heterogeneous catalysts for Lewis acid and oxidation reactions: roles of structural defects and stability. ACS Catal. 2, 2060-2065. doi: 10.1021/cs300345b
Dhakshinamoorthy, A., Opanasenko, M., Čejka, J., and Garcia, H. (2013). Metal organic frameworks as solid catalysts in condensation reactions of carbonyl groups. Adv. Synth. Cat. 355, 247-268.

Eddaoudi, M., Kim, J., Rosi, N., Vodak, D., Wachter, J., O'Keeffe, M., et al. (2002). Systematic design of pore size and functionality in isoreticular MOFs and their application in methane storage. Science 295, 469-472. doi: 10.1126/science. 1067208

Emeis, C. A. (1993). Determination of integrated molar extinction coefficients for infrared-absorption bands of pyridine adsorbed on solid acid catalysts. J. Catal. 141, 347-354. doi: 10.1006/jcat.1993.1145

Freeman, F. (1981). Properties and reactions of ylidenemalononitriles. Chem. Rev. 80, 329-350. doi: 10.1021/cr60326a004

Green, B., Crane, R. I., Khaidem, I. S., Leighton, R. S., Newaz, S. S., and Smyser, T. E. (1985). Synthesis of steroidal 16, 17-fused unsaturated delta-lactones. J. Org. Chem. 50, 640-644. doi: 10.1021/jo00205a016

Hoefnagel, A. J., Gunnewegh, E. A., Downing, R. S., and van Bekkum, H. (1995). Synthesis of 7-hydroxycoumarins catalyzed by solid acid catalysts. J. Chem. Soc. Chem. Commun. 225-226. doi: 10.1039/c39950000225

Jiang, J., Yu, J., and Corma, A. (2010). Extra-large-pore zeolites: bridging the gap between micro and mesoporous structures. Angew. Chem. Int. Ed. Engl. 49, 3120-3145. doi: 10.1002/anie. 200904016

Joshi, U. D., Joshi, P. N., Tamhankar, S. S., Joshi, V. V., Rode, C. V., and Shiralkar, V. P. (2003). Effect of nonframework cations and crystallinity on the basicity of $\mathrm{NaX}$ zeolites. Appl. Catal. A Gen. 239, 209-220. doi: 10.1016/S0926-860X(02)00391-5

Kalita, P., Sathyaseelan, B., Mano, A., Javaid Zaidi, S. M., Chari, M. A., and Vinu, A. (2010). Synthesis of superacid-functionalized mesoporous nanocages with tunable pore diameters and their application in the synthesis of coumarins. Chem. Eur. J. 16, 2843-2851. doi: 10.1002/chem.200902531

Karimi, B., and Behzadnia, H. (2011). Periodic mesoporous silica chloride (PMSCl) as an efficient and recyclable catalyst for the Pechmann reaction. Catal. Commun. 12, 1432-1436. doi: 10.1016/j.catcom.2011.05.019

Karimi, B., and Zareyee, D. (2008). Design of a highly efficient and water-tolerant sulfonic acid nanoreactor based on tunable ordered porous silica for the von Pechmann reaction. Org. Lett. 10, 3989-3992. doi: $10.1021 / \mathrm{ol} 8013107$

Kumbhare, R. M., and Sridhar, M. (2008). Magnesium fluoride catalyzed Knoevenagel reaction: an efficient synthesis of electrophilic alkenes. Catal. Comm. 9, 403-405. doi: 10.1016/j.catcom.2007.07.027

Lai, M., Ng, C. P., Martin-Aranda R., and Yeung, K. L. (2003). Knoevenagel condensation reaction in zeolite membrane microreactor. Micropor.Mesopor. Mater. 66, 239-252. doi 10.1016/j.micromeso.2003.09.014

Lau, W. N., Yeung, K. L., and MartinAranda, R. (2008). Knoevenagel condensation reaction between benzaldehyde and ethyl acetoacetate in microreactor and membrane microreactor. Micropor. Mesopor. Mater. 115, 156-163. doi 10.1016/j.micromeso.2007.12.036

Li, C.-J. (2005). Organic reactions in aqueous media with a focus on carbon-carbon bond formations: a decade update. Chem. Rev. 105, 3095-3166. doi: 10.1021/cr030009u

Li, G. X., Gu, Y. L., Ding, Y., Zhang, H. P., Wang, J. M., Gao, Q., et al. (2004). Wells-Dawson type molybdovanadophosphoric heteropolyacids catalyzed Prins cyclization of alkenes with paraformaldehyde under mild conditions-a facile and efficient method to 1, 3-dioxane derivatives. J. Mol. Catal. A: Chem. 218, 147-152. doi: 10.1016/j.molcata.2004.04.021

Li, H., Eddaoudi, M., O'Keeffe, M., and Yaghi, O. M. (1999). Design and synthesis of an exceptionally stable and highly porous metal-organic framework. Nature 402, 276-279. doi: $10.1038 / 46248$

Li, T. S., Zhang, Z. H., Yang, F., and Fu, C. G. (1998). Montmorillonite clay catalysis. Part 7.1 an environmentally friendly procedure for the synthesis of coumarins via Pechmann condensation of phenols with ethyl acetoacetate. J. Chem. Res. (S) 1, 38-39.

Opanasenko, M., Dhakshinamoorthy, A., Shamzhy, M., Nachtigall, P., Horacek, M., Garcia, H., et al. (2013a). Comparison of the catalytic activity of MOFs and zeolites in Knoevenagel condensation. Catal. Sci. Technol. 3, 500-507. doi: 10.1039/c2cy20586f

Opanasenko, M., Shamzhy, M., and Čejka, J. (2013b). Solid acid catalysts for coumarin synthesis by the Pechmann reaction: MOFs versus zeolites. ChemCatChem 5, 1024-1031. doi: 10.1002/cctc.201200232

Paillaud, J.-L., Harbuzaru, B., and Patarin, J. (2004). Extra-large-pore zeolites with two-dimensional channels formed by 14 and 12 rings. Science 304, 990-992. doi: 10.1126/science.1098242

Patil, M. V., Yadav, M. K., and Jasra, R. V. (2007). Prins condensation for synthesis of nopol from P-pinene and paraformaldehyde on novel Fe-Zn double metal cyanide solid acid catalyst. J. Mol. Catal. A Chem. 273, 39-47. doi: 10.1016/j.molcata.2007.03.054

Pérez-Mayoral, E., Musilová, Z., Gil, B., Marszalek, B., Položij, M., Nachtigall, P., et al. (2012). Synthesis of quinolines via Friedlander reaction catalyzed by CuBTC metal-organic-framework. Dalton Trans. 44, 4036-4044. doi: 10.1039/c2dt11978a

Pillai, U. R., and Sahle-Demessie, E. (2004). Mesoporous iron phosphate as an active, selective and recyclable catalyst for the synthesis of nopol by Prins condensation. Chem. Commun. 7, 826-827. doi: $10.1039 / \mathrm{b} 313747 \mathrm{c}$

Rajasekhar Pullabhotla, V. S. R., Rahman, A., and Jonnalagadda, S. B. (2009). Selective catalytic Knoevenagel condensation by $\mathrm{Ni}-$ $\mathrm{SiO}_{2}$ supported heterogeneous catalysts: an environmentally benign approach. Catal. Comm. 10, 365-369. doi: 10.1016/j.catcom.2008.09.021

Reddy, T. I., and Verma, R. S. (1997). Rare-earth (RE) exchanged $\mathrm{NaY}$ zeolite promoted Knoevenagel condensation. Tetrahedron Lett. 38, 1721-1724. doi: 10.1016/S0040-4039(97)00180-9

Russell, A., and Frye, J. R. (1955). 2, 6-dihydroxyacetophenone. Org. Synth. 3, 281-283.

Sabou, R., Hoelderich, W. F., Ramprasad, D., and Weinand, R. (2005). Synthesis of 7hydroxy-4-methyleoumarin via the Pechmann reaction with Amberlyst ion-exchange resins as catalysts. J. Catal. 232, 34-37. doi: 10.1016/j.jcat.2005.02.002

Selvaraj, M., and Choe, Y. (2010). Well ordered two-dimensional SnSBA-15 catalysts synthesized with high levels of tetrahedral tin for highly efficient and clean synthesis of nopol. Appl. Catal. A Gen. 373, 186-191. doi: 10.1016/j.apcata. 2009.11.014

Selvaraj, M., and Sinha, P. K. (2010). Highly selective and clean synthesis of nopol over well-ordered 
mesoporous tin silicate catalysts. New J. Chem. 34, 1921-1929. doi: 10.1039/c0nj00080a

Shamzhy, M. V., Shvets, O. V., Opanasenko, M. V., Kurfiřtova, L., Kubička, D., and Čejka, J. (2013). Extra-large-pore zeolites with UTL topology: control of the catalytic activity by variation in the nature of the active sites. Chem. Cat. Chem. 5, 1891-1898.

Shamzhy, M. V., Shvets, O. V., Opanasenko, M. V., Yaremov, P. S., Sarkisyan, L. G., Chlubná, P., et al. (2012). Synthesis of isomorphously substituted extralarge pore UTL zeolites. J. Mater. Chem. 22, 15793-15803. doi: 10.1039/c2jm31725g

Shanthan, R. P., and Venkataratnam, R. V. (1991). Zinc chloride as a new catalyst for Knoevenagel condensation. Tetrahedron Lett. 32, 5821-5822. doi: 10.1016/S0040-4039(00)93564-0

Shvets, O. V., Kasian, N., Zukal, A., Pinkas, J., and Čejka, J. (2010). The role of template structure and synergism between inorganic and organic structure directing agents in the synthesis of UTL zeolite. Chem. Mater. 22, 3482-3495. doi: $10.1021 / \mathrm{cm} 1006108$

Shvets, O. V., Shamzhy, M. V., Yaremov, P. S., Musilová, Z., Procházková, D., and Čejka, J. (2011). Isomorphous introduction of boron in germanosilicate zeolites with UTL topology. Chem. Mater. 23, 2573-2585. doi: 10.1021/cm200105f

Shvets, O. V., Zukal, A., Kasian, N., Žilková, N., and Čejka, J. (2008). The role of crystallization parameters for the synthesis of germanosilicate with UTL Topology. Chem. Eur. J. 14, 10134-10140. doi: 10.1002/chem.200800416

Sudha, S., Venkatachalam, K., Vishnu Priya, S., Herbert Mabel, J., Palanichamy, M., and Murugesan, V. (2008). Single step synthesis of coumarin derivatives over Al-MCM-41 and its supported catalysts under solvent-free condition. J. Mol. Catal. A. 291, 22-29. doi: 10.1016/j.molcata.2008.04.021

Tietze, L. F., and Beifuss, U. (1991). "The Knoevenagel reaction," in Comprehensive Organic Synthesis, eds B. M. Trost and I. Fleming (Oxford: Pergamon Press), 341-394.

Torviso, R., Mansilla, D., Belizán, A., Alesso, E., Moltrasio, G., Vázquez, P., et al. (2008). Catalytic activity of Keggin heteropolycompounds in the Pechmann reaction. Appl. Catal. A 339, 53-60. doi: 10.1016/j.apcata.2008.01.020

Tyagi, B., Mishra, M. K., and Jasra, R. V. (2007). Synthesis of 7-substituted 4-methyl coumarins by Pechmann reaction using nano-crystalline sulfated-zirconia. J. Mol. Catal. A 276, 47-56. doi: 10.1016/j.molcata.2007.06.003

Weinmann, I. (1997). "History of the development and applications of coumarin and coumarin-related compounds," in Coumarins: Biology, Applications and Mode of Action, eds R. O. Kennedy and R. D. Thornes (Chichester: Wiley Press), $1-22$.

Williams, J. T., Bahia, P. S., and Snaith, J. S. (2002). Synthesis of 3, 4-disubstituted piperidines by carbonyl ene and prins cyclizations: a switch in diastereoselectivity between Lewis and Bronsted acid catalysts. Org. Lett. 4, 3727-3730. doi: 10.1021/ol0266929

Woods, L. L., and Sapp, J. (1962). A new one-step synthesis of substituted coumarins. J. Org. Chem. 27, 3703-3705. doi: 10.1021/jo01057a519

Yadav, J. S., Reddy, B. V. S., and Bhaishya, G. (2003). $\mathrm{InBr}_{3}$ [bmim] $\mathrm{PF}_{6}$ : a novel and recyclable catalytic system for the synthesis of 1, 3-dioxane derivatives. Green Chem. 5, 264-266. doi: 10.1039/b212044p

Yadav, M. K., and Jasra, R. V. (2006). Synthesis of nopol from betapinene using $\mathrm{ZnCl}_{2}$ impregnated Indian Montmorillonite. Catal.
Commun. 7, 889-895. doi: 10.1016/j.catcom.2006.04.002

Conflict of Interest Statement: The authors declare that the research was conducted in the absence of any commercial or financial relationships that could be construed as a potential conflict of interest.

Received: 06 June 2013; paper pending published: 02 July 2013; accepted: 23 July 2013; published online: 28 August 2013.

Citation: Shamzhy M, Opanasenko $M$, Shvets $O$ and Čejka J (2013) Catalytic performance of MetalOrganic-Frameworks vs. extra-large pore zeolite UTL in condensation reactions. Front. Chem. 1:11. doi: 10.3389/ fchem.2013.00011

This article was submitted to Green and Environmental Chemistry, a section of the journal Frontiers in Chemistry.

Copyright (c) 2013 Shamzhy, Opanasenko, Shvets and Čejka. This is an open-access article distributed under the terms of the Creative Commons Attribution License (CC BY). The use, distribution or reproduction in other forums is permitted, provided the original author(s) or licensor are credited and that the original publication in this journal is cited, in accordance with accepted academic practice. No use, distribution or reproduction is permitted which does not comply with these terms. 


\section{APPENDIX}

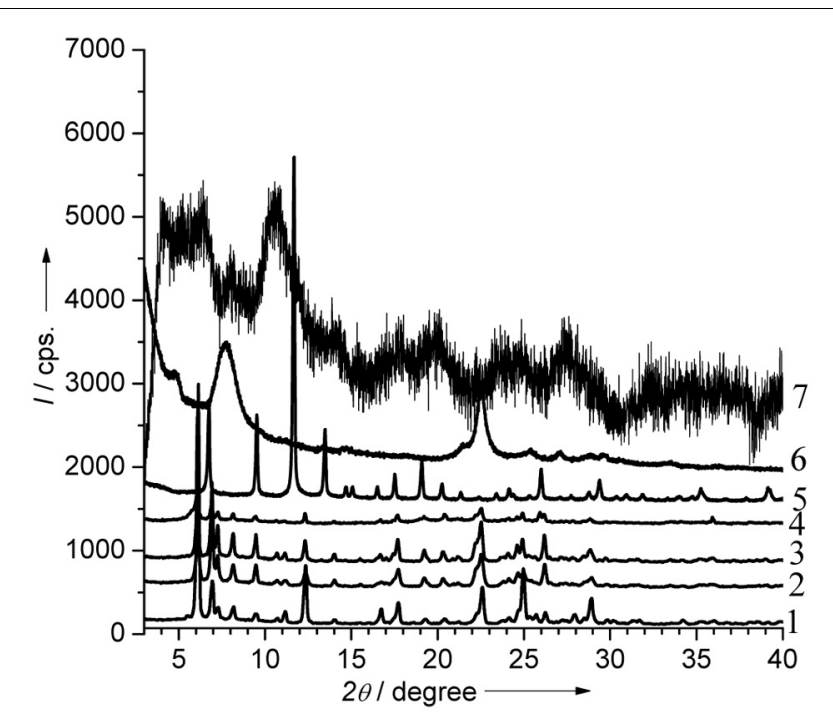

FIGURE A1 | X-ray powder diffraction patterns of the catalysts. 1-(B)UTL, 2-(AI)UTL, 3-(Ga)UTL, 4-(Fe)UTL, 5- $\mathrm{Cu}_{3}(\mathrm{BTC})_{2}$, 6-(Al)beta, 7-Fe(BTC).

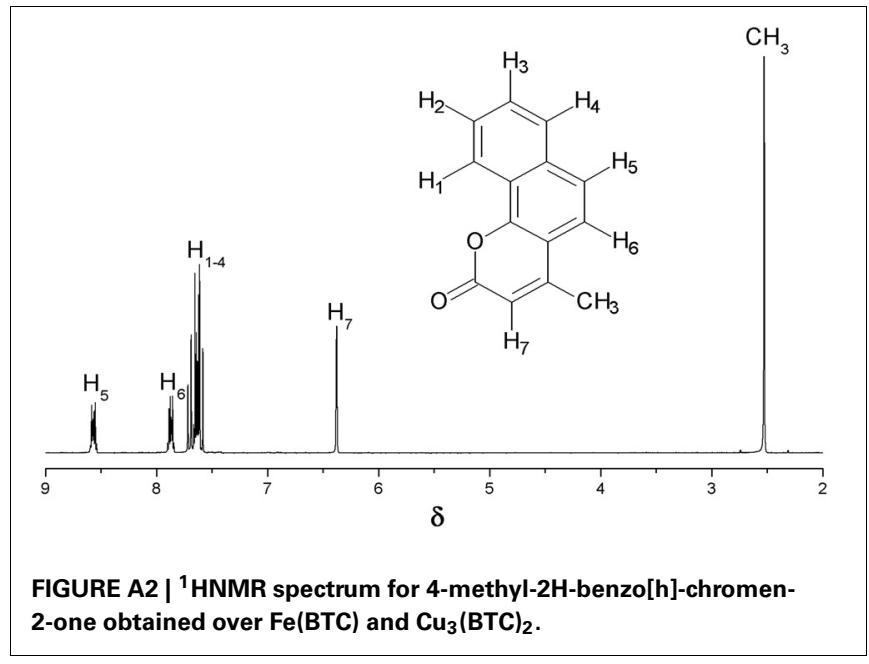

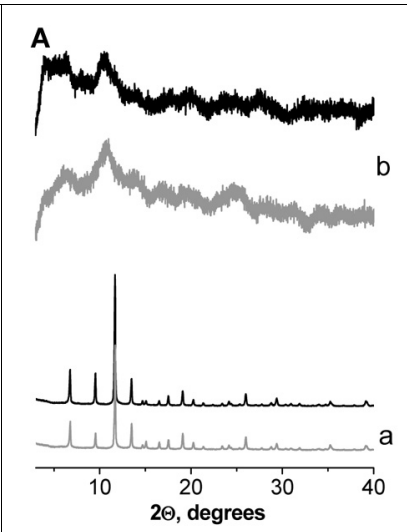

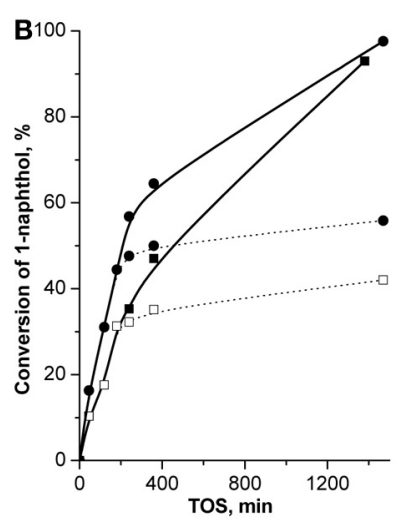

FIGURE A3 | XRD patterns of $\mathrm{Cu}_{3}(\mathrm{BTC})_{2}$ (a) and $\mathrm{Fe}(\mathrm{BTC})$ (b) before (-) and after (-) $24 \mathrm{~h}$ TOS in Pechmann condensation of 1-naphthol at $130^{\circ} \mathrm{C}(\mathrm{A})$; leaching test: TOS dependence of the conversion of 1-naphthol in Pechmann condensation of 1-naphthol (full line-standard experiment, dotted line-leaching test, $T=130^{\circ} \mathrm{C}$ ) for $-\square-\mathrm{Cu}_{3}(\mathrm{BTC})_{2},-\bullet-\mathrm{Fe}(\mathrm{BTC})(\mathrm{B})$.

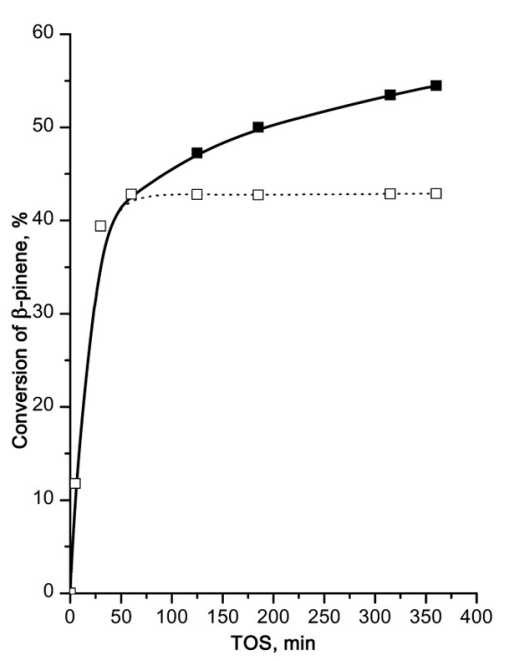

FIGURE A4 | Leaching test: TOS dependence of the conversion of $\beta$-pinene in Prins condensation with PF (full line-standard experiment, dotted line-leaching test, $T=80^{\circ} \mathrm{C}$ ) for $\mathrm{Fe}(\mathrm{BTC})$. 